\title{
Jejunal Perforation following Screening Colonoscopy
}

\author{
Lakshmi Pasumarthy ${ }^{a}$ James Srour ${ }^{\mathrm{b}}$ Dennis Johnson ${ }^{\mathrm{c}}$ \\ Departments of a Medicine, ${ }^{b}$ Gastroenterology and 'Surgery, York Hospital, \\ York, Pa., USA
}

\section{Key Words}

Colonoscopy $\cdot$ Jejunal diverticulum $\cdot$ Perforation

\begin{abstract}
Colonoscopy is rarely associated with complications such as colonic perforation. Perforation of the small bowel is extremely rare, especially if the procedure is done without therapeutic interventions. Several factors are associated with this entity. Perforation of the ileum has been reported, but proximal jejunal perforation secondary to rupture of jejunal diverticulum during colonoscopy has not been reported. We present the case of an 88-year-old patient who developed abdominal pain after undergoing colonoscopy without any additional interventions. Urgent exploration revealed perforation of the proximal jejunum secondary to rupture of a jejunal diverticulum. No therapy or biopsies were undertaken during the colonoscopy, which are known predisposing factors.
\end{abstract}

\section{Introduction}

Colonic perforation is an uncommon complication following diagnostic colonoscopy, occurring at the frequency of $0.1-0.2 \%$ [1]. Perforation of the small intestine is even less common. The proposed mechanisms include direct trauma from excessive insufflation of air and improper use of electrocautery during polypectomy. Diseased segments of intestine and adhesions are well recognized predisposing factors.

\section{Case Presentation}

An 88-year-old lady underwent colonoscopy for follow-up of colonic polyps. She was found to have no new polyps, but had extensive diverticular disease throughout the sigmoid and the descending colon. No biopsies were done. She had no complaints after the procedure and was discharged home. Later in the evening she developed severe abdominal pain and was taken to the emergency room.

On examination, her temperature was $99.8^{\circ} \mathrm{F}$, heart rate 70 beats $/ \mathrm{min}$, blood pressure $156 / 63 \mathrm{~mm}$ $\mathrm{Hg}$, oxygen saturation $94 \%$ on room air. She was in moderate distress. Examination was remarkable for 
a firm, distended lower abdomen with tenderness in the epigastric region as well as bilateral lower quadrants. Bowel sounds were sparse. Blood work showed a white blood cell count of $16,500 / \mathrm{mm}^{3}$, an absolute neutrophil count of $14,850 / \mathrm{mm}^{3}$, a hemoglobin of $14.1 \mathrm{mg} / \mathrm{dl}$ and platelets of $258,000 / \mathrm{mm}^{3}$. Renal panel was within normal limits.

Abdominal X-ray showed multiple air fluid levels. CT of the abdomen/pelvis showed evidence of free air with free fluid adjacent to the transverse colon (fig. 1). The patient was taken to the operating room and explored through a midline incision. Upon opening the peritoneum, there was evidence of bile stained fluid. It did not smell feculent. The colon was explored first from the cecum to the rectum and no perforation was found. The small bowel was then run from the ligament of Treitz to the terminal ileum. In the proximal jejunum, multiple very thin diverticuli were encountered. Some measured close to $3 \mathrm{~cm}$. A very clear perforation was found in one of these diverticuli on the mesenteric side of the bowel. This segment of small bowel was resected using surgical staplers and a primary reanastomosis was successfully performed. Further exploration of the stomach, lesser sac, and duodenum revealed no evidence of perforation. The abdomen was irrigated, suctioned and closed. Dissection was performed on either side of the small bowel, between the mesentery and the small bowel. The mesenteric defect was closed with interrupted sutures. No other abnormalities were seen.

Pathology confirmed perforated diverticulum associated with marked acute inflammation and fibrinopurulent serosal exudate.

The patient recovered well from the surgical repair and was released a week later from the hospital.

\section{Discussion}

Perforation of jejunum in the context of a diagnostic colonoscopy where no therapy or biopsy was undertaken has not been reported so far.

A literature review of cases from 1976 to the present was done using PubMed. Perforation of diseased jejunum during colonoscopy has only been reported once previously by Nijhawan et al. [2] with ileal perforation being reported six times before. In two cases ileal perforation occurred after snare polypectomy with cautery $[3,4]$. Dense adhesions were reported as the predisposing factor in three cases [5-7]. Acute-on-chronic ischemia predisposed the ileal segment to perforation in one case (table 1).

Air insufflation has also been reported as a mechanism for perforation of the colon or the ileum. The amount of insufflated air required to perforate the colon varies from segment to segment, with larger pressures required for the sigmoid colon as compared with the cecum. Diseased segment of the intestine predisposes it to perforation as seen in the case reported by Nijhawan et al. [2] as well as the ileal perforation case reported by Chau et al. [8]. The diseased segment of jejunum with ischemic changes and loss of mucosal integrity may have allowed dissection of air through the subserosa, allowing for perforation. Other proposed mechanisms for intestinal perforation were incompetent ileocecal valve, in addition to air insufflation.

In the case by presented by Lambert et al. [3], it was felt that the cautery current transmitted through the cecal wall to the small bowel. Another report [5] revealed a case of ileal perforation during a colonoscopy in which excessive amounts of pneumatic pressure were used to insufflate the colon.

Jejunal diverticula are uncommon, with a $0.3-1.3 \%$ autopsy incidence. In contrast to true congenital Meckel's diverticulum, these acquired diverticula originate from the mesenteric border of the bowel where the arteries enter through the bowel wall. Perforation of a jejunal diverticulum is a rare complication and has been reported, but not in the context of a colonoscopy where no biopsies were done. 
In our case, the proposed mechanism of jejunal perforation is insufflation of excessive amounts of air. Large jejunal diverticulae may have been a predisposing factor.

Table 1. Site and proposed mechanism of perforation

\begin{tabular}{|c|c|c|}
\hline Site & Predisposing factors & Mechanism of perforation \\
\hline Jejunum (Nijhawan et al.) & inflammation & $\begin{array}{l}\text { insufflation of large amount of air, } \\
\text { incompetent ileocecal valve }\end{array}$ \\
\hline Ileum (Lambert et al.) & $\begin{array}{l}\text { snare polypectomy and } \\
\text { cautery }\end{array}$ & $\begin{array}{l}\text { current transmitted through the cecal } \\
\text { wall to the small bowel }\end{array}$ \\
\hline Ileum (Erdman et al.) & $\begin{array}{l}\text { snare polypectomy and } \\
\text { cautery }\end{array}$ & $\begin{array}{l}\text { current transmitted through the cecal } \\
\text { wall to the small bowel }\end{array}$ \\
\hline Ileum (Nemeh et al.) & $\begin{array}{l}\text { dense fixed pelvic adhe- } \\
\text { sions }\end{array}$ & $\begin{array}{l}\text { the adhesions created a fixed point that } \\
\text { tore as torque and pressure were used to } \\
\text { advance the colonoscope }\end{array}$ \\
\hline Ileum (Razzak et al.) & dense adhesions & insufflation of large amounts of air \\
\hline $\begin{array}{l}\text { Ileum (Gonzalez Ramirez } \\
\text { et al.) }\end{array}$ & dense adhesions & \\
\hline Ileum (Chau et al.) & underlying ischemia & insufflation of large amounts of air \\
\hline
\end{tabular}

Fig. 1. CT scan of abdomen/pelvis with evidence of free air with free fluid adjacent to the transverse colon.

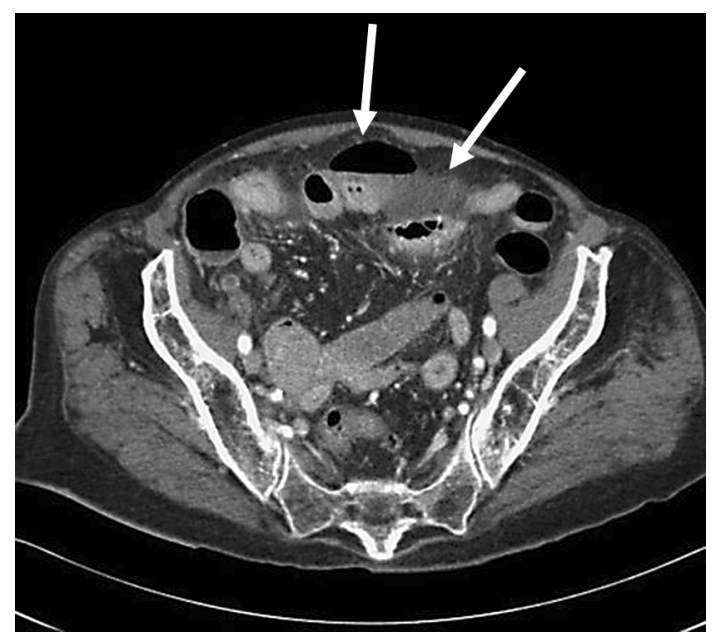




\section{References}

1 Waye JD, Kahn O, Auerbach ME: Complications of colonoscopy and flexible sigmoidoscopy. Gastrointest Endosc Clin N Am 1996;6:343-377.

-2 Nijhawan S, Rai RR, Bhargava N, Nepalia S, Pokharna DS: Jejunal perforation: a complication of colonoscopy. Tropi Gastroenterol 1994;15:225-227.

-3 Lambert A, Nguyen SQ, Byrn JC, Fishman EW, Shen HY: Small-bowel perforation after colonoscopy. Gastrointest Endosc 2007;65:352-353.

4 Erdman LH, Boggs HW Jr, Slagle GW: Electrical ileal perforation: an unusual complication of colonoscopy. Dis Colon Rectum 1979;22:501-502.

5 Razzak IA, Millan J, Schuster MM: Pneumatic ileal perforation: an unusual complication of colonoscopy. Gastroenterology 1976;2:268-271.

-6 Nemeh HW, Ranzinger MR, Dutro JA: Mid-ileal perforation secondary to colonoscopy. Am Surg 1994;60:228-229.

7 Gonzalez Ramirez A, Avila S, Lopez-Roses L, Lancho A, Santos E, Soto S, Penin S: Small bowel obstruction and perforation after colonoscopy. Endoscopy 2003;35:192.

8 Chau TN, Ng C, Lau LK, Lai ST, Yuen H: Delayed mid-ileal perforation secondary to acute-on-chronic ischaemia after a diagnostic colonoscopy. Scand J Gastroenterol 1998;33:1002-1004. 